\title{
Thermodynamic Modeling of the Rheological Behavior of PEG Aqueous Solutions as a Function of the Solute Molecular Weight and Shear Stress, at $298.15 \mathrm{~K}$ and $0.1 \mathrm{MPa}$
}

\author{
Raphael da C. Cruz ${ }^{1, *}$, Márcio J.E. de M. Cardoso ${ }^{2}$ and Oswaldo E. Barcia² \\ ${ }^{1}$ Laboratory of Thermodynamics and Rheology, Department of Physical Chemistry, Institute of Chemistry, \\ Fluminense Federal University, Outeiro de São João Batista, $s / n^{\circ}$, Campus do Valonguinho, Centro, CEP: \\ 24020-150. Niterói, RJ, Brasil \\ ${ }^{2}$ Laboratory of Physical Chemistry of Liquids and Electrochemistry, Department of Physical Chemistry, \\ Institute of Chemistry, Federal University of Rio de Janeiro, Centro de Tecnologia, Bloco A, sala 411, Cidade \\ Universitária, CEP: 21949-900. Rio de Janeiro, RJ, Brasil
}

\begin{abstract}
This work presents a study of the influence of the molecular weight on the thermodynamic modeling of the viscosity of non-newtonian polymer solutions. The employed model is based on the absolute rate theory of Eyring and on the solution theory of McMillan-Mayer. The Soave-Redlich-Kwong equation of state was adopted for the calculation of the excess molar McMillan-Mayer free energy derived from the osmotic pressure of the solution. The model presents parameters that take account separately the different possibilities of interaction in the macromolecular environment. As the tertiary structure of a polymer molecule can be affected by applied shear stress, only the parameters related with the intramolecular interactions are dependent of the shear stress. The experimental rheological curves for different molecular weights of polyethylene glycol aqueous solutions have been measured at several concentrations, within the whole polymer solubility range, at $298.15 \mathrm{~K}$ and $0.1 \mathrm{MPa}$. The dependence on the molecular weight for all parameters of the model was analyzed and characterized. The dependence of the shear sensitive parameters on the shear stress was also studied.
\end{abstract}

Keywords: Viscosity, rheology, thermodynamics, modeling, polymer solutions, polyethylene glycol.

\section{INTRODUCTION}

Knowledge of the viscosity of polymer solutions is fundamental in the design of processes and equipments in the chemical and pharmaceutical industry, in the oil extraction and production units and in the research of new products. With this aim, several approaches to describe the rheological behavior of polymer solutions have been proposed.

The viscosity of non-newtonian solutions can be calculated by means of a continuum mechanistic approach [1,2], as for example, through the RivlinSawyers theory [2,3] and concepts such as Finger tensor [4] and Cauchy-Green tensor [5], leading to equations such as the Oldroyd-B and the (Kaye)Bernstein, Kearsley, Zapas - (K)-BKZ [6-8]. However, as the description of these models are very rigorous, they frequently contain a large number of parameters which are difficult or, in some cases, impossible to be determined by fitting the experimental viscosity data $[9,10]$.

\footnotetext{
*Address correspondence to this author at the Laboratory of Thermodynamics and Rheology, Department of Physical Chemistry, Institute of Chemistry, Fluminense Federal University, Outeiro de São João Batista, $s / n^{\circ}$, Campus do Valonguinho, Centro, CEP: 24020-150. Niterói, RJ, Brasil; Tel: +55-21-26292231; Fax: +55-21-2629-2129; E-mail: rdccruz@vm.uff.br
}

A second approach for the modeling of the viscosity of a non-newtonian solution is to consider the molecular modeling. In the last 50 years, several dynamic theories have been proposed to this aim [915]. These dynamic theories are based on the diffusion-convection Fokker-Planck equation, on the stochastic Langevin equation or on the Smoluchowski equation $[9,15]$. Because of the closure condition that appears in these models, different methodologies have been employed for breaking the equation hierarchy, leading to different types of constitutive theories [9] that can be applied to very dilute, semi dilute or entangled polymer solutions, according to the theory used. Despite the precise description of this approach, the complexity makes its use difficult in industrial and practical rheological applications.

Another way to describe the rheological behavior of the non-newtonian solutions is through the phenomenological models $[16,17]$. Nevertheless, the close agreement between the calculated and the experimental results in these models, the equations and their parameters do not present any more fundamental justification. Moreover, the adjusted parameters, valid for a given solute and solvent, depend on the solution composition, temperature and pressure. These models are also restricted, in general, to the range of shear rate to which the model 
parameters have been fitted. It should be stressed that, when using such a model, the region of its validity must be carefully obeyed. Therefore, by changing the system, we can modify completely the parameters and even the equation used in the rheological description.

The great advantage of the models based on the absolute rate theory of Eyring [18-20] is to present a reasonably rigorous description of the polymer system under study, together with close agreement between the calculated and the experimental viscosity values due to their semi-empirical character. It should be remarked that recently the Eyring equation has been received a solid theoretical foundation from the nonequilibrium thermodynamics [21].

On other hand, fundamentally it is known, due to the well-known Mark-Houwink equation [16,22,23], that the viscosity of a polymer solution and the molecular weight of the polymer are closely linked. Normally, increasing the polymer molecular weight, the solution viscosity also increases, because the capability of entanglements between polymeric chains increases, making the polymer more aggregated.

Curiously, the dependences between the polymer molecular weight and the parameters of the models above mentioned have not been investigated so well. More frequently, the dependence between the polymer molecular weight and the solution viscosity is more focused than the dependence with the individual parameters.

Exceptions to this, particularly with polyethylene glycol solutions, are the works of Ninni et al. [24] and of González-Tello et al. [25]. In the former [24], the authors employed the Kumar equation to describe the kinematic viscosity of newtonian polyethylene glycol solutions. They report that both Kumar parameters show an exponential increase with the polymer molecular weight. In the González-Tello et al. work [25], the authors also proposed a model to describe the dynamic viscosity of newtonian polyethylene glycol solutions. This model has four adjustable parameters and all of them present a linear profile with the polymer molecular weight. We have not found works where the parameters of non-newtonian models were studied in function of the polymer molecular weight.

In a previous paper [26], the authors presented a model based on the absolute rate theory of Eyring [1820] and on the solution theory of McMillan-Mayer [2731] for calculating the rheological behavior of nonnewtonian polymer solutions. This model presents an explicit shear stress dependence of the viscosity of the solution and was applied to aqueous solutions of just one polyethylene glycol (PEG) molecular weight. In the present paper the authors examine the application of this model to aqueous solutions of four different PEGs, in order to investigate the effect of the size of the polymeric chain on the model parameters. The dependence of the parameters on the shear is also studied.

We should remark that one could imagine, incidentally, that it is not more than a mere gigantic curve fitting problem, but it is not true, because all the parameters of the alleged fitting problem have a fundamental justification for their existence and for their form presented elsewhere [26]. More than that, the influence of the increase and decrease of the polymer molecular weight and of the increase and decrease of the applied shear stress are carefully analyzed and discussed in terms of the possible interactions between different parts of the same polymer chain, between separated polymer chains or between the polymer chain and the solvent molecules. Thus, the affirmation that the present work is simply a fitting problem is a nailf understanding of the essence of this work.

The organization of the rest of this article is as follows. In Sect. 2 some aspects of the experimental procedure are given. Sect. 3 presents the results, the analyses of the data and the discussion. Finally, in Sect. 4 our conclusions are summarized. In the Appendix all the details about the experimental considerations and carful are detailed and explained. In the Supplementary Material all the experimental and calculated results used in this study are listed and presented as tables or spreadsheets.

\section{EXPERIMENTAL SECTION}

In this work, we have studied four different PEGs in aqueous solutions: PEG3000, PEG6000, PEG10000 and PEG20000. All PEGs were supplied by Merck. The manufacturer provided molecular weight distribution ranges and melting point ranges are [2700 - 3300] $\mathrm{g} / \mathrm{mol}$ and $[50-56]^{\circ} \mathrm{C}$ (PEG3000); [5000 - 7000] g/mol and [56 - 61 $]^{\circ} \mathrm{C}$ (PEG6000); [9000 - 12500] g/mol and $[58-63]^{\circ} \mathrm{C}$ (PEG10000), and about $20000 \mathrm{~g} / \mathrm{mol}$ and $[58-63]^{\circ} \mathrm{C}$ (PEG20000). The polymers were used without further purification and were stored in a desiccator over silica gel and under vacuum.

The rheological measurements were performed in a ThermoHaake RheoStress 1 rheometer (Karlshuhe, 
Germany) with a Z34 titanium concentric cylinder rotor. The rheometer was coupled with a ThermoHaake Phoenix P1-CP25 thermostatic bath to control the temperature within $0.01 \mathrm{~K}$. All the measurements taken in this work were purely rotational (not oscillatory), obtained by means of the Controlled Stress (CS) mode, in order to give a larger range of accessible shear stresses, and with step increments.

In order to procedure the minimization of the model and to study the influence of the PEG molecular weight on the model parameters, measurements of rheological behavior of the solutions were needed. Therefore, we prepared nine different solutions of PEG3000 in the concentrations of $0.3767,0.4268,0.4853,0.5116$, $0.5425,0.5715,0.6012,0.6306$, and $0.6598 \mathrm{~g} / \mathrm{cm}^{3}$; eleven solutions of PEG6000 in the concentrations of $0.3156,0.3721,0.4282,0.4566,0.4854,0.5136$, $0.5433,0.5722,0.6011,0.6310$, and $0.6606 \mathrm{~g} / \mathrm{cm}^{3}$; ten solutions of PEG10000 in the following concentrations: $0.2030,0.2633,0.3189,0.3739,0.4288,0.4849$, $0.5124,0.5415,0.5716$, and $0.6030 \mathrm{~g} / \mathrm{cm}^{3}$; and twelve solutions of PEG20000 in the concentrations of 0.1607 , $0.2101,0.2611,0.3153,0.3716,0.4282,0.4579$, $0.4869,0.5149,0.5446,0.5714$, and $0.6032 \mathrm{~g} / \mathrm{cm}^{3}$. The solutions were prepared by mass using a digital balance (Chyo YMC, model JK-180, Kyoto, Japan), with an uncertainty of $\pm 0.1 \mathrm{mg}$, in airtight stoppered bottles. The water employed in the preparation of the solutions was filtered and distilled in a Tecnal TE-178 quartz distiller. The electric conductivity of the water did not exceed $5.0 \mu \mathrm{S} / \mathrm{cm}$. The estimated error in the mass fraction is $<1.0 \times 10^{-4}$. In order to convert the polymer weight fractions to the polymer molar concentrations necessary for modeling purposes, a volumetric study of these systems was performed and is presented elsewhere [32,33].

The viscosity average molecular weight $[32,34]$ of each PEG was also determined. For the PEG3000 it was found to be $3565 \mathrm{~g} / \mathrm{mol}$; for the PEG6000 it was $6892 \mathrm{~g} / \mathrm{mol}$; in the case of the PEG10000 it was 12065 $\mathrm{g} / \mathrm{mol}$, and for the PEG20000 the value found was $25907 \mathrm{~g} / \mathrm{mol}$. These values of average molecular weight were the values of molecular weights employed in the model calculation procedure.

\section{RESULTS AND DISCUSSION}

The viscosity values under very low shear stress conditions were not considered. In these cases, the uncertainty due to the low electric current, and to the low torque of the drive-cup motor, combined with the low rotation speeds make accurate measurements very difficult. Furthermore, some measurements show that in these conditions of low shear stress, there is a light increase in the viscosity with the increase of the shear stress. Recently, some authors have attributed this behavior to a change in the structure of the solution related to the shear $[35,36]$. However, it can be shown that these transitions can be explained by the boundary layer that is not fully developed [37-39] in the entire gap, i.e., the boundary condition of null azimuthal velocity in the resolution of the Navier-Stokes equation to the Couette flow problem is satisfied for a radius smaller than the external one for this rotational velocity and for this system. Thus, the smaller thickening of the flowing layer makes the viscosity presents an apparent maximum value.

At high shear, some solutions have presented a linear increase in the viscosity with increase in the shear stress, configuring a clear reversible shear thickening (reversible dilatancy) behavior. In recent years, some authors have verified this kind of behavior in other systems [40]. The reasons for the shear thickening behavior at high shear conditions are still unclear, and various explanations have been proposed to explain the phenomenon. One them is the orderdisorder mechanism proposed by Hoffmann [41-43]. Another possibility is the formation of a non-equilibrium, quaternary, self-organized microstructure that develops under strong flows, denoted as "hydroclusters" $[44,45]$. Accordingly, the shear thickening behavior is the result of the formation of a stiffer inner structure due to the entanglements of polymer coils and the increase in the intermolecular interactions, as the shear rate rises.

In this study, the reversible shear thickening was observed for the solutions with a concentration of 0.5716 and $0.6030 \mathrm{~g} / \mathrm{cm}^{3}$ for PEG10000, and also for those with a concentration of $0.4282,0.4579,0.4869$, $0.5149,0.5446$, and $0.5714 \mathrm{~g} / \mathrm{cm}^{3}$ for PEG20000. In all cases where the reversible shear thickening was observed, the values beyond the pseudoplastic region were neglected, that is, the values were modeled only until the beginning of the reversible shear thickening.

Therefore, the shear stress range for each viscosity measurement depends on the solution concentration and on the molecular weight of the PEGs studied. Due to the fact that the ratio (and its square) between the inner and outer cylinder is greater than the null ratio between the outer and inner angular velocity, and that this is a necessary but insufficient condition for the flow instabilities to occur [46], special care was taken to 
inspect and to suppress any possible bifurcations. We should remark that despite the observation, no bifurcations, except those that appear after the onset of reversible shear thickening, were observed. No drag or edge effects, or viscous dissipation, were observed either in our measurements, as described in the Appendix together all the carful and experimental considerations that must be accounted in the realization of the measurements.

In Figure $\mathbf{1}$ it is possible to observe a pseudoplastic behavior for a $0.5124 \mathrm{~g} / \mathrm{cm}^{3}$ PEG10000 solution. This viscosity curve is analogous for all PEGs and for all polymer concentrations, that is, for all systems investigated the pseudoplastic pattern was observed. This profile was analogous to the one reported previously [26]. The experimental data shown in the figures is also presented in the Supplementary Material.

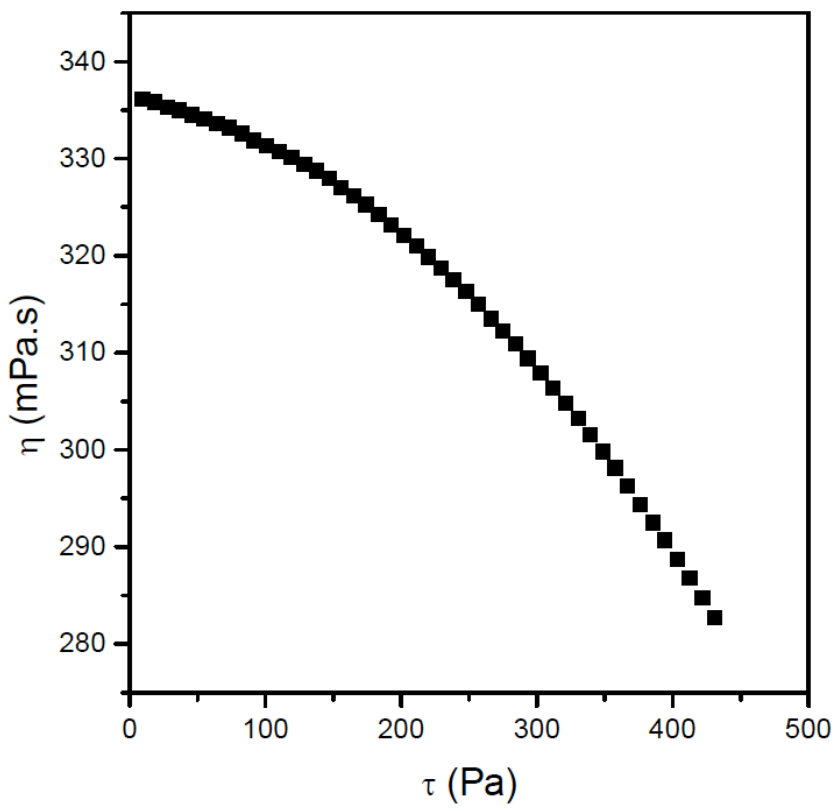

Figure 1: Viscosity curve of $0.5124 \mathrm{~g} / \mathrm{cm}^{3}$ PEG10000 aqueous solutions.

We have made a linear regression of a polynomial at the experimental data in order to get the viscosityshear stress data to be used in the model parameter fitting [26].

A total of one thousand four hundred and eighteen (1418) diagrams of viscosity versus polymer concentration have been correlated by the model previously developed by the authors [26], for different shear stress, at $298.15 \mathrm{~K}$ and $0.1 \mathrm{MPa}$. We would remark that the deviations between the calculated values and the experimental viscosity values were smaller than the experimental error ( up to 10\%) [26,32,47-49]. As mentioned before, this model is based on the absolute rate theory of Eyring [18-20], and on the solution theory of McMillan-Mayer [27-29] by means of the so-called osmotic equilibrium formulation [30,31]. According to this model, the expression for calculation of the viscosity of a polymer solution is given as follows [26,32]:

$$
\begin{aligned}
& \eta=\eta_{1}+\eta_{1} A_{o} Z c \times \frac{\sinh \left[B / c\left(1+A_{1} c+A_{2} c^{2}+\ldots\right)\right]}{\sinh (B / c)} \times \\
& \left\{\left[\left(\frac{1-b Z c}{Z-b Z c}\right) \cdot\left(\frac{1+b Z c}{1+b c}\right)^{a / b R T}\right] \times \exp (Z-1)\right\}
\end{aligned}
$$

where $\eta$ and $\eta_{1}$ are the dynamic viscosity of the solution and of the pure solvent, respectively; $c$ is the polymer molar concentration; $Z$ is the so-called osmotic compressibility factor or Bjerrum's osmotic coefficient and is calculated by $[17,26,31,32,50]$

$Z=\frac{1}{1-b c}-\frac{a c}{R T(1+b c)}$

The $a, b, A_{0}, A_{1}, A_{2}, \ldots$ are the adjustable parameters of the model. It is important to observe that the both first parameters are shear independent, and come from the Soave-Redlich-Kwong equation of state used in the model [26,32]. $A_{\circ}$ is another shear independent parameter and comes from the definition of an ideal polymer solution [26,32]. The parameters $\left(A_{1}, A_{2}, A_{3}, A_{4}, \ldots\right)$ were called hydrodynamic parameters and are sensitive to the applied shear stress. These latter parameters come from the observation that even in very low molar concentrations polymer solutions can exhibit accentuated nonnewtonian behavior of flow [51], and were defined by the assumption that $[26,32]$

$$
\frac{\mathrm{c}_{\mathrm{id}}}{\mathrm{c}}=1+\sum_{\mathrm{n}=1}^{+\infty} \mathrm{A}_{\mathrm{n}} \mathrm{c}^{\mathrm{n}}=1+\mathrm{A}_{1} \mathrm{c}+\mathrm{A}_{2} \mathrm{c}^{2}+\mathrm{A}_{3} \mathrm{c}^{3}+\cdots
$$

where $c_{\text {id }}$ is the molar concentration of an ideal polymer solution.

In the study of the different polyethylene glycol solutions, it was verified that for aqueous solutions of PEG3000 and PEG6000, the addition of orders higher than the second order, in the power series in the argument of hyperbolic sine, did not present any improvement in the accuracy of the calculated values of viscosity. For aqueous solutions of PEG10000, a 
cubic term was needed to accomplish close agreement between the calculated and experimental viscosity values. In the case of aqueous solutions of PEG20000, close agreement was obtained only with the inclusion of a fourth order term in the series expansion.

Due to the knowledge of these dependences, the model can also be used to predict the viscosity values of $P E G$ aqueous solutions in the range of molecular weights and shear stresses of this study, i.e., between 3000 up to $20000 \mathrm{~g} / \mathrm{mol}$ and between 10.0 up to 853.0 $\mathrm{Pa}$, at $298.15 \mathrm{~K}$ and $0.1 \mathrm{MPa}$.

As mentioned before, the average molecular weight of each PEG was considered as being the viscosity average molecular weight. No consideration was made relative to the polydispersity.

The adjustment of the model parameters was performed by the simplex-type algorithm of the Nelder and Mead [52,53], where the objective function, $F_{\text {obj, }}$, employed in the determination of the adjustable parameters of the model was the same one used previously $[26,32]$, that is, the sum of the quadratic deviations between the calculated and experimental results for each shear stress value:

$\mathrm{F}_{\mathrm{obj}}=\sum_{\mathrm{i}=1}^{\mathrm{ND}}\left(\eta_{\mathrm{calc}, \mathrm{i}}-\eta_{\text {exp,i }}\right)^{2}$

where ND is the number of the viscosity experimental data available for each shear stress, $\eta_{\text {calc }}$ is the viscosity calculated by the model and $\eta_{\exp }$ is the experimental viscosity, naturally, both for each shear stress value.

To turn the minimization procedure a consistent system, at least five input experimental data (five concentration-viscosity pairs, for a given shear stress value) were needed for the parameter fitting of the viscosity of aqueous solutions of PEG3000 and of aqueous solutions of PEG6000. For aqueous solutions of PEG10000, a minimum set of six input experimental data were informed. For aqueous solutions of PEG20000 a minimum of seven concentration-viscosity pairs of experimental data were lacked. Taking this into account, the computing operational shear stress ranges were from 22.0 $\mathrm{Pa}$ up to $100.0 \mathrm{~Pa}$ for PEG3000 aqueous solutions; from $10.0 \mathrm{~Pa}$ up to $246.0 \mathrm{~Pa}$ for PEG6000 aqueous solutions; from 10.0 $\mathrm{Pa}$ up to 367.0 $\mathrm{Pa}$ for PEG10000, and from 10.0 $\mathrm{Pa}$ up to $853.0 \mathrm{~Pa}$ for PEG20000 aqueous solutions. It must be remarked that the lower limit in the stress range for investigations of aqueous solutions of PEG3000 is higher, due to the fact that for shear stress values lower than $22.0 \mathrm{~Pa}$, bifurcations were observed during the measurements, as mentioned before. The higher shear stress limits are different in the four molecular weights studied, due to the fact that the maximum rotation speed sustained by the rheometer $(1200 \mathrm{rpm})$ is achieved at different shear stresses, increasing with the concentration and molecular weight of PEG.

The agreement between the calculated and the experimental results can be seen in Figure 2 and in Tables 1 to 4 , for all four PEGs, at $80.0 \mathrm{~Pa}$ of shear stress.

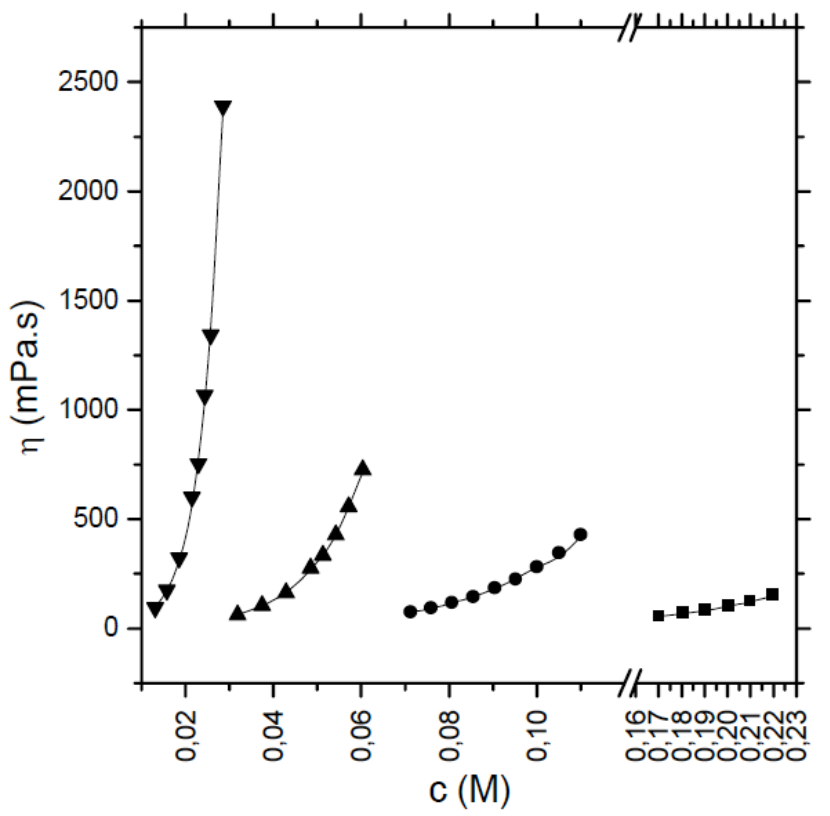

Figure 2: Experimental and calculated viscosity values at shear stress of $80.0 \mathrm{~Pa}$, for different studied PEG aqueous solutions. Experimental data: (ロ) PEG3000; (@) PEG6000;

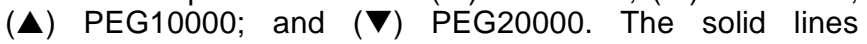
represent the calculated values.

Table 1: Experimental, Calculated Viscosity Values and Absolute Relative Deviations for a Shear Stress of 80.0 Pa of PEG3000 Aqueous Solutions

\begin{tabular}{|c|c|c|c|}
\hline $\mathbf{c}(\mathbf{M})$ & $\eta_{\exp }$ (mPa.s) & $\eta_{\text {calc }}$ (mPa.s) & ARD (\%) \\
\hline \hline 0.17052 & 53.65 & 55.421 & 3.31 \\
\hline 0.18083 & 68.44 & 67.880 & 0.82 \\
\hline 0.19049 & 82.39 & 82.302 & 0.11 \\
\hline 0.20038 & 100.62 & 100.483 & 0.14 \\
\hline 0.21021 & 122.61 & 122.786 & 0.14 \\
\hline 0.21993 & 149.86 & 149.853 & 0.01 \\
\hline \multicolumn{3}{|c|}{ MRSD (\%) } & 1.40 \\
\hline
\end{tabular}


Table 2: Experimental, Calculated Viscosity Values and Absolute Relative Deviations for a Shear Stress of 80.0 Pa of PEG6000 Aqueous Solutions

\begin{tabular}{|c|c|c|c|}
\hline $\mathbf{c}(\mathbf{M})$ & $\eta_{\exp }$ (mPa.s) & $\eta_{\text {calc }}(\mathbf{m P a} . \mathbf{s})$ & ARD (\%) \\
\hline \hline 0.07137 & 72.60 & 73.733 & 1.56 \\
\hline 0.07610 & 90.29 & 92.731 & 2.70 \\
\hline 0.08090 & 113.98 & 116.983 & 2.64 \\
\hline 0.08560 & 139.89 & 146.542 & 4.75 \\
\hline 0.09055 & 180.42 & 184.902 & 2.49 \\
\hline 0.09537 & 220.46 & 229.445 & 4.08 \\
\hline 0.10018 & 278.46 & 279.198 & 0.26 \\
\hline 0.10516 & 341.37 & 330.071 & 3.31 \\
\hline 0.11010 & 424.43 & 426.015 & 0.37 \\
\hline \multicolumn{3}{|c|}{ MRSD (\%) } & 2.85 \\
\hline
\end{tabular}

Table 3: Experimental, Calculated Viscosity Values and Absolute Relative Deviations for a Shear Stress of 80.0 Pa of PEG10000 Aqueous Solutions

\begin{tabular}{|c|c|c|c|}
\hline $\mathbf{c}(\mathbf{M})$ & $\eta_{\exp }(\mathbf{m P a} . \mathbf{s})$ & $\eta_{\text {calc }}(\mathbf{m P a} . \mathbf{s})$ & ARD (\%) \\
\hline \hline 0.03189 & 60.08 & 62.123 & 3.41 \\
\hline 0.03739 & 102.49 & 102.258 & 0.23 \\
\hline 0.04289 & 161.52 & 166.251 & 2.93 \\
\hline 0.04849 & 275.04 & 268.644 & 2.33 \\
\hline 0.05124 & 332.74 & 337.323 & 1.38 \\
\hline 0.05415 & 428.66 & 427.010 & 0.39 \\
\hline 0.05716 & 554.96 & 555.820 & 0.15 \\
\hline 0.06031 & 725.39 & 715.450 & 1.37 \\
\hline \multicolumn{3}{|c|}{ MRSD (\%) } & 1.92 \\
\hline
\end{tabular}

Table 4: Experimental, Calculated Viscosity Values and Absolute Relative Deviations for a Shear Stress of 80.0 Pa of PEG20000 Aqueous Solutions

\begin{tabular}{|c|c|c|c|}
\hline $\mathbf{c}(\mathbf{M})$ & $\eta_{\exp }(\mathbf{m P a} . \mathbf{s})$ & $\eta_{\text {calc }}(\mathbf{m P a} . \mathbf{s})$ & ARD (\%) \\
\hline \hline 0.01305 & 91.84 & 96.909 & 5.52 \\
\hline 0.01576 & 174.06 & 170.996 & 1.76 \\
\hline 0.01858 & 319.81 & 309.838 & 3.12 \\
\hline 0.02141 & 599.33 & 565.009 & 5.73 \\
\hline 0.02290 & 751.48 & 773.452 & 2.92 \\
\hline 0.02434 & 1064.89 & 1044.071 & 1.95 \\
\hline 0.02574 & 1342.02 & 1383.366 & 3.08 \\
\hline 0.02857 & 2388.90 & 2358.299 & 1.28 \\
\hline \multicolumn{3}{|c|}{ MRSD (\%) } & 3.53 \\
\hline
\end{tabular}

To evaluate the agreement between the calculated and the experimental viscosities, we employed the absolute relative deviations, ARD. The mean relative standard deviation (MRSD) represents the global deviation for a given shear stress value, i.e., for all concentrations of each PEG solution in a given shear stress value. Finally, we use also the overall MRSD ( $\overline{M R S D}$ ), that is the average of all MRSD over all shear stress values. These deviations are thus defined by:

$(\mathrm{ARD})_{\mathrm{c}, \tau}=\left|\frac{\eta_{\mathrm{calc}, \mathrm{i}}-\eta_{\text {exp,i }}}{\eta_{\text {exp }, \mathrm{i}}}\right|$

by

$(\operatorname{MRSD})_{\tau}=\sqrt{\frac{1}{\mathrm{ND}}\left[\sum_{\mathrm{i}=1}^{\mathrm{ND}}\left(\frac{\eta_{\text {calc }, \mathrm{i}}-\eta_{\text {exp }, \mathrm{i}}}{\eta_{\text {exp }, \mathrm{i}}}\right)^{2}\right]}$

and by

$\overline{\mathrm{MRSD}}=\frac{1}{\mathrm{~N} \tau} \sum_{\mathrm{i}=1}^{\mathrm{N} \tau} \mathrm{MRSD}_{\mathrm{i}}$

where $N \tau$ is the number of shear stresses used in the calculation. As previously stated, all the experimental, calculated and respective deviation values are presented in the Supplementary Material.

For PEG3000 solutions, the MRSD values varied from $0.2 \%$ to $1.5 \%$, with the overall MRSD value equal to $0.72 \%$. For PEG6000, the MRSD values were in the range of $2 \%$ and $7 \%$, and the overall MRSD was equal to $4.37 \%$. For PEG10000, the MRSD ranged from $1 \%$ to $4.5 \%$, with the overall equal to $1.93 \%$, and for PEG20000 solutions, the MRSD range was from 3\% to $7.5 \%$, and the MRSD was $3.35 \%$.

The three model parameters that are shear stressindependent $\left(\mathrm{a}, \mathrm{b}\right.$ and $\mathrm{A}_{\circ}$ ) are presented in Table $\mathbf{5}$.

They can be represented in terms of the PEG molecular weight according to the following exponential curve, obtained by non-linear regression and represented in Figures $\mathbf{3}$ and $\mathbf{4}$,

$\mathrm{a}, \mathrm{b}$ or $\mathrm{A}_{\mathrm{o}}=\mathrm{D}_{\mathrm{o}}+\mathrm{D}_{1} \cdot \exp \left(\frac{\mathrm{D}_{2}}{\mathrm{M}_{\eta}}\right)$

where $M_{\eta}$ is the viscosity average molecular weight of the polymer. The coefficients $D_{1}, D_{2}$ and $D_{3}$ are presented in Table 6. 
Table 5: Shear Independent Parameters of the Model

\begin{tabular}{|c|c|c|c|}
\hline & $A_{\circ}\left(\mathrm{cm}^{3} / \mathrm{g}\right)$ & $\mathrm{a}\left(\mathrm{Pa} / \mathrm{cm}^{6} \cdot \mathrm{mol}^{2}\right)$ & $\mathrm{b}\left(\mathrm{cm}^{3} / \mathrm{g}\right)$ \\
\hline PEG3000 & 49361.87 & -1.81796 & 1585.43 \\
\hline PEG6000 & 145745.43 & -18.24053 & -3969.38 \\
\hline PEG10000 & 352530.56 & -43.94145 & -6333.46 \\
\hline PEG20000 & 1822360.46 & -51.47299 & -14789.27 \\
\hline
\end{tabular}

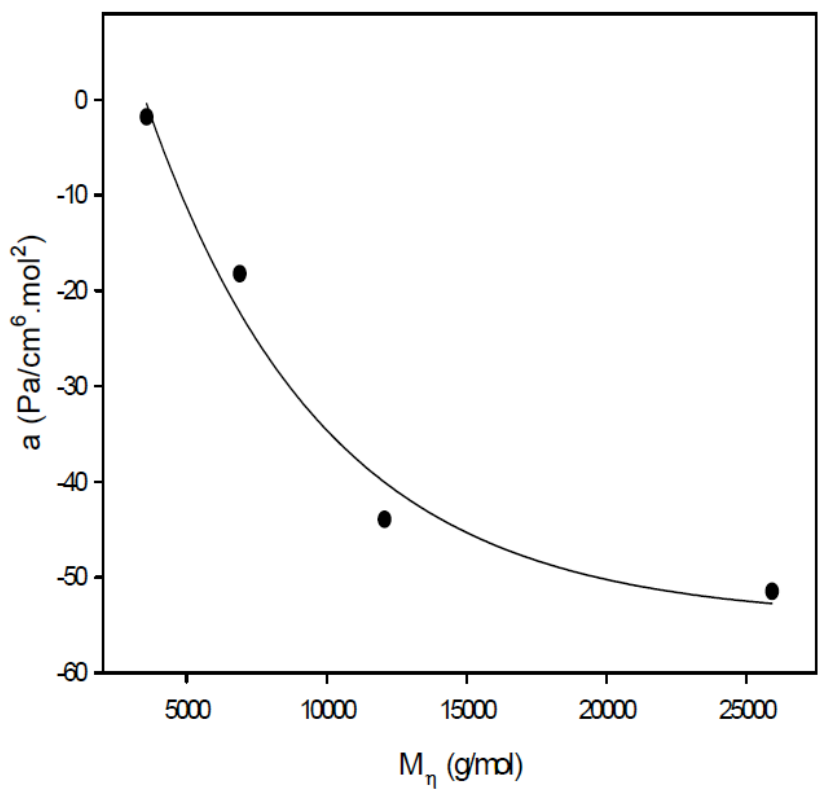

Figure 3: Dependence of the shear-independent parameter a on the PEG molecular weight.

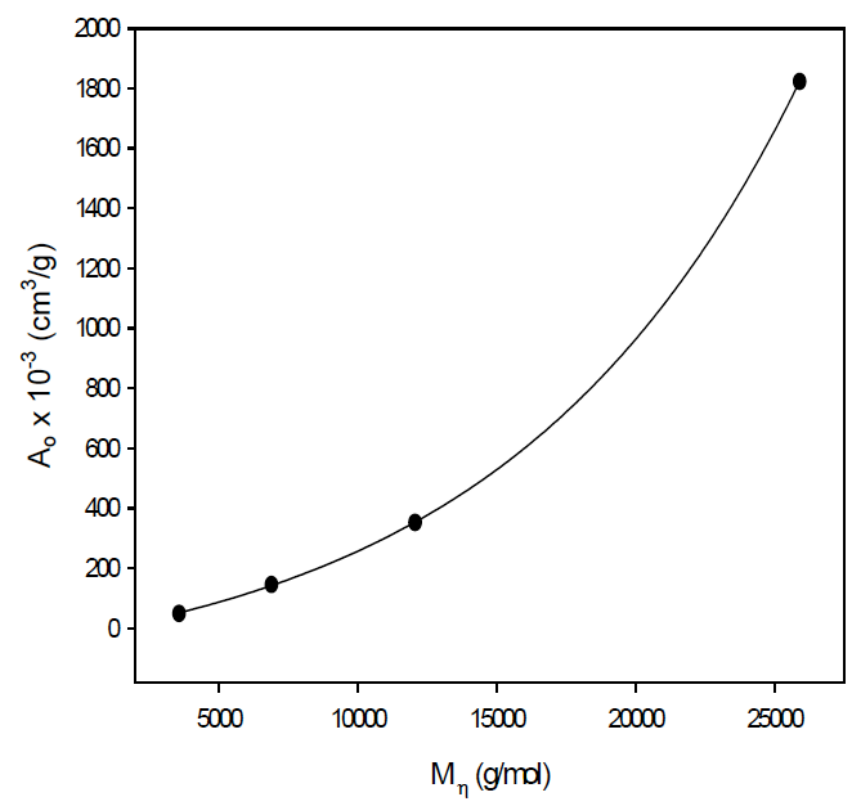

Figure 4: Dependence of the shear-independent parameter $A_{\circ}$ on the PEG molecular weight.

The parameter $A_{\circ}$ characterizes the infinite dilution polymer-solvent interaction. We can verify by the
Figure 5 that this parameter is related to the intrinsic viscosity of the polymers [34]. It is a reasonable conclusion due to the fact that the $A_{\circ}$ parameter came from an expression of the ideal dilute solution [26,32], which is in essence the Huggins expression [54-56]. In the case that the ideal solution is dilute, but not so dilute to assure that the Huggins linear expression is valid, more terms in the Huggins expression are necessary [23].

Table 6: Coefficients of the Exponential Dependence of the Shear Stress Invariant Parameters with the Viscosity Average Molecular Weight

\begin{tabular}{|c|c|c|c|}
\hline & $\mathbf{D}_{0}{ }^{\dagger}$ & $\mathbf{D}_{1}{ }^{\dagger}$ & $\mathbf{D}_{2} \times 10^{5 \neq}$ \\
\hline \hline $\mathrm{A}_{\mathrm{o}}\left(\mathrm{cm}^{3} / \mathrm{g}\right)$ & -195812.8868 & 176935.1911 & 9.3957 \\
\hline $\mathrm{a}\left(\mathrm{Pa} / \mathrm{cm}^{6} \cdot \mathrm{mol}^{2}\right)$ & -54.4156 & 94.0552 & -15.5703 \\
\hline $\mathrm{b}\left(\mathrm{cm}^{3} / \mathrm{g}\right)$ & -21543.2812 & 27214.2975 & -5.3002 \\
\hline
\end{tabular}

${ }^{\dagger}$ The units of $D_{0}$ and $D_{1}$ are $\mathrm{cm}^{3} / g$ for $A_{0}$ and $b$. For the $D_{0}$ and $D_{1}$ of $a$, the units are $\mathrm{Pa} / \mathrm{cm}^{6} \cdot \mathrm{mol}^{2}$.

${ }^{\ddagger}$ The unit of $D_{2}$ is $\mathrm{g} / \mathrm{mol}$ for $A_{0}$, a and $b$.

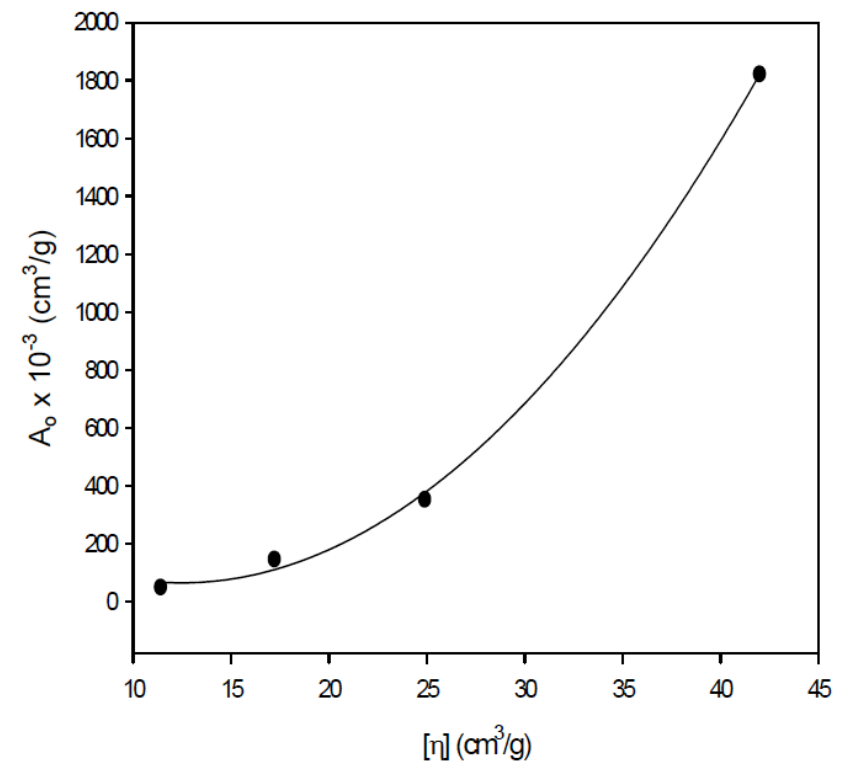

Figure 5: Relationship between the model parameter $A_{\circ}$ and the intrinsic viscosity of the different PEG molecular weights [34]. The solid line represents the linear regression of $A_{\circ}$ in relation to $[\eta]$. 


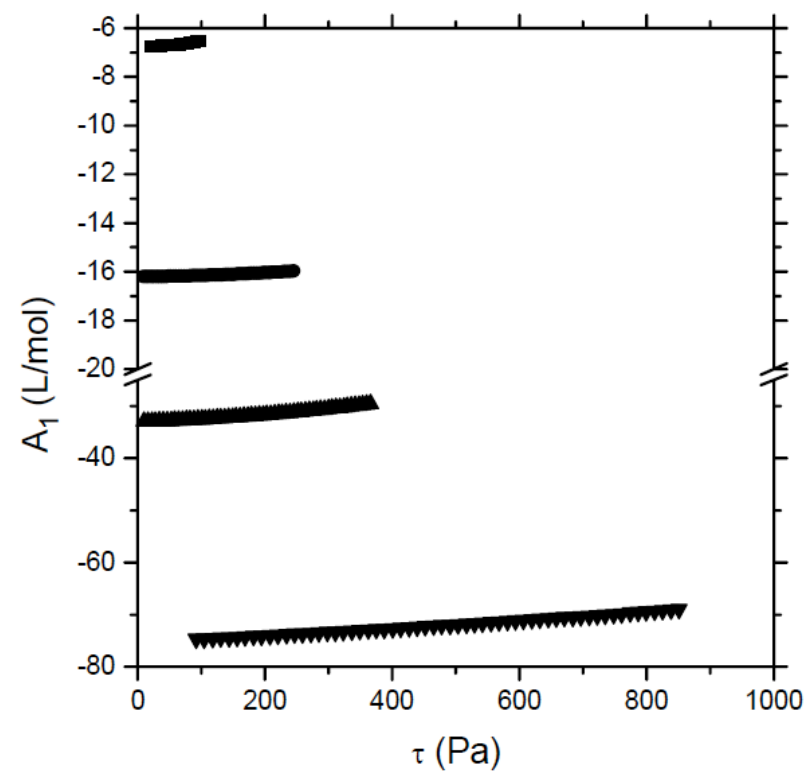

Figure 6: Dependence of the $A_{1}$ parameter on the shear stress for different PEG aqueous solutions: (ם) PEG3000;

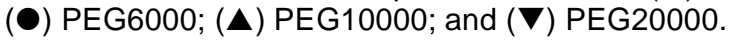

The behavior of the shear dependent hydrodynamic parameters $\left(A_{1}, A_{2}, A_{3}\right.$ and $\left.A_{4}\right)$ with the shear stress obey

$\mathrm{A}_{1}, \mathrm{~A}_{2}, \mathrm{~A}_{3}$ or $\mathrm{A}_{4}=\sum_{\mathrm{n}=0}^{2} \mathrm{P}_{\mathrm{n}} \tau^{\mathrm{n}}$

for all four PEG aqueous solutions investigated in this work and is presented in Figure 6 for $A_{1}$. The coefficients of these polynomials are presented in Table 7, where $P_{0}, P_{1}$ and $P_{2}$ are, respectively, the zeroth, first and second term of the polynomial. We observe that $A_{1}$ and $A_{3}$ are parabolas with positive concavity, while $A_{2}$ and $A_{4}$ are parabolas with negative ones. Thus, these results show that the power series in the argument of the hyperbolic sines are alternated. It should also be remarked that the amplitude of variation of the hydrodynamic parameters increases with the molecular weight of the PEG. This may be explained by the sense that the larger polymeric chains are more sensitive to the deformations in their tertiary structure than the shorter ones.

The variations of these parameters with molecular weight are represented by exponential-type curve, illustrated in Figure 7 for $A_{2}$, for a fixed shear stress value of $100.0 \mathrm{~Pa}$. The coefficients of these curves will vary from one shear stress value to another, because these parameters are shear variants, but the general form is the same.

Another possibility is to express the double dependence of the hydrodynamic parameters $\left(A_{1}, A_{2}\right.$, $A_{3}$ and $A_{4}$ ) on the polymer molecular weight and on the shear stress by the surfaces represented in direct trihedral, as in Figure 8 for $A_{2}$. The surfaces for $A_{1}, A_{2}$ and $A_{3}$ were obtained the triangulation method of Renka-Cline [57], and the surface for $A_{4}$ was built by non-linear regression.

\section{CONCLUSIONS}

In this work we have applied the previously proposed model [26] for four PEGs with different

Table 7: Coefficients of the Polynomial Dependence of $A_{1}, A_{2}, A_{3}$ and $A_{4}$ with the Shear Stress Obtained by Linear Regression

\begin{tabular}{|c|c|c|c|c|}
\hline Polymer & Hydrodynamic Parameter & $\mathbf{P}_{0}^{\dagger}$ & $P_{1} \times 10^{3 \ddagger}$ & $P_{2} \times 10^{5^{*}}$ \\
\hline \multirow{2}{*}{ PEG3000 } & $\mathrm{A}_{1} \times 10^{-3}\left(\mathrm{~cm}^{3} / \mathrm{mol}\right)$ & -6.7928894 & -0.0843995 & 2.3463074 \\
\hline & $\mathrm{A}_{2} \times 10^{-6}\left(\mathrm{~cm}^{6} / \mathrm{mol}^{2}\right)$ & 11.947598 & 0.14150139 & -10.104646 \\
\hline \multirow{2}{*}{ PEG6000 } & $\mathrm{A}_{1} \times 10^{-3}\left(\mathrm{~cm}^{3} / \mathrm{mol}\right)$ & -16.242964 & 0.37192784 & 0.23779184 \\
\hline & $\mathrm{A}_{2} \times 10^{-6}\left(\mathrm{~cm}^{6} / \mathrm{mol}^{2}\right)$ & 65.293325 & -3.3695802 & -2.1436266 \\
\hline \multirow{3}{*}{ PEG10000 } & $\mathrm{A}_{1} \times 10^{-3}\left(\mathrm{~cm}^{3} / \mathrm{mol}\right)$ & -33.051398 & 3.43350975 & 1.6335223 \\
\hline & $\mathrm{A}_{2} \times 10^{-6}\left(\mathrm{~cm}^{6} / \mathrm{mol}^{2}\right)$ & 276.32836 & -120.41114 & -54.685713 \\
\hline & $\mathrm{A}_{3} \times 10^{-9}\left(\mathrm{~cm}^{9} / \mathrm{mol}^{3}\right)$ & -52.283706 & 1055.1465 & 457.87486 \\
\hline \multirow{4}{*}{ PEG20000 } & $\mathrm{A}_{1} \times 10^{-3}\left(\mathrm{~cm}^{3} / \mathrm{mol}\right)$ & -75.338791 & 5.6813195 & 0.19495063 \\
\hline & $\mathrm{A}_{2} \times 10^{-6}\left(\mathrm{~cm}^{6} / \mathrm{mol}^{2}\right)$ & 1522.0496 & -396.50361 & -12.028613 \\
\hline & $\mathrm{A}_{3} \times 10^{-9}\left(\mathrm{~cm}^{9} / \mathrm{mol}^{3}\right)$ & 9019.6486 & 6696.9142 & 205.07140 \\
\hline & $\mathrm{A}_{4} \times 10^{-12}\left(\mathrm{~cm}^{12} / \mathrm{mol}^{4}\right)$ & -421691.70 & 3806.8233 & -133.44709 \\
\hline
\end{tabular}

${ }^{\dagger}$ The units of $P_{0}$ are $\mathrm{cm}^{3} / \mathrm{mol}_{\text {for }} A_{1} ; \mathrm{cm}^{6} / \mathrm{mol}^{2}$ for $A_{2} ; \mathrm{cm}^{9} / \mathrm{mol}^{3}$ for $A_{3}$ and $\mathrm{cm}^{12} / \mathrm{mol}^{4}$ for $A_{4}$.

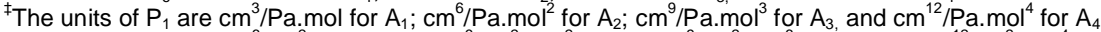

*The units of $\mathrm{P}_{2}$ are $\mathrm{cm}^{3} / \mathrm{Pa}^{2}$.mol for $\mathrm{A}_{1} ; \mathrm{cm}^{6} / \mathrm{Pa}^{2} \cdot \mathrm{mol}^{2}$ for $\mathrm{A}_{2} ; \mathrm{cm}^{9} / \mathrm{Pa}^{2} \cdot \mathrm{mol}^{3}$ for $\mathrm{A}_{3}$ and $\mathrm{cm}^{12} / \mathrm{Pa}^{2} \cdot \mathrm{mol}^{4}$ for $\mathrm{A}_{4}$. 
molecular weights in order to verify the influence of the chain size in the parameters of the referred model.

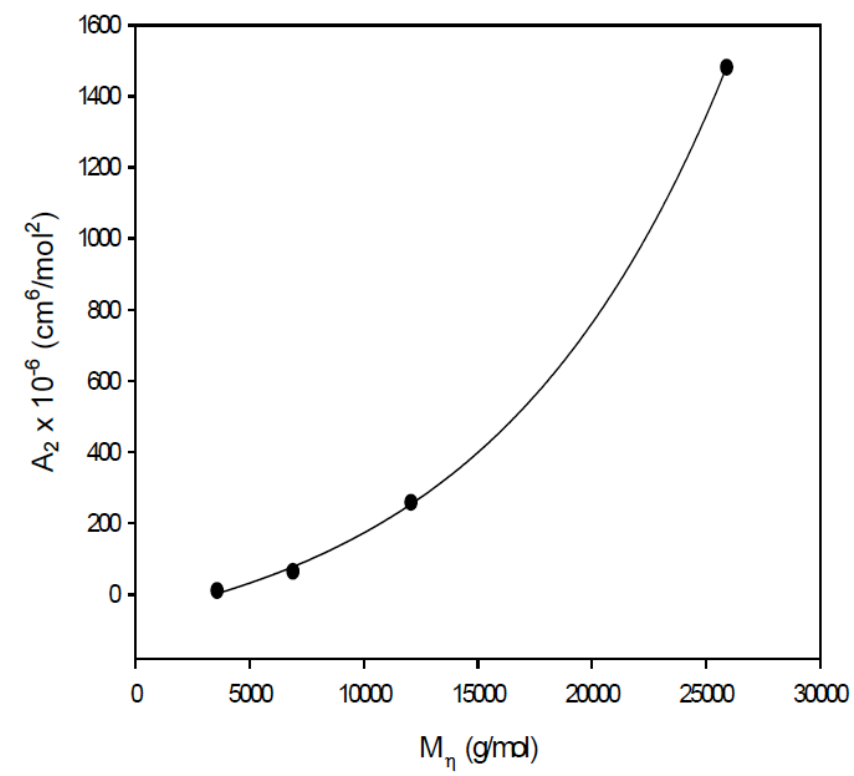

Figure 7: Dependence of the $A_{2}$ parameter on the PEG molecular weight, at a shear stress of $100.0 \mathrm{~Pa}$. The solid line represents the non-linear regression.

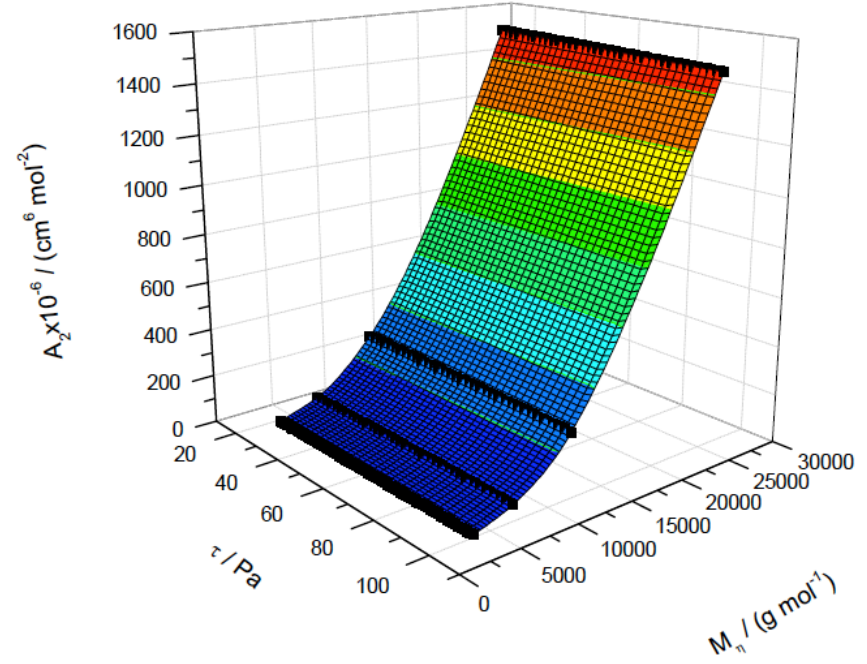

Figure 8: Surface representing the double dependence of the $\mathrm{A}_{2}$ parameter on the PEG molecular weight and on the shear stress.

To perform this study, we had to measure the viscosity in function of the shear stress for each molecular weight. In the achievement of the rheological measurements, special care was taken to avoid other phenomena that could represent interferences in the quality of the results, such as viscous dissipation, turbulence, slippage and others.

The agreements between the calculated viscosity values and the experimental ones were closer than the experimental error, with different mean relative standard deviations being obtained for each shear stress value and PEG molecular weight. These results show that the model is adequate to describe the simultaneous dependence of the viscosity of the PEG aqueous solutions with different molecular weights, on shear stress and on concentration, at $298.15 \mathrm{~K}$ and 0.1 MPa.

The dependences of the model parameters on the molecular weight of PEG were also found and analyzed. The values of the shear-independent parameters $\left(a, b\right.$ and $\left.A_{0}\right)$ were shown to vary exponentially with the PEG molecular weight. The other parameters $\left(A_{1}, A_{2}, A_{3}\right.$ and $\left.A_{4}\right)$ also present exponential profiles for their dependence on the molecular weight, but quadratic profiles for their dependence on the shear stress.

\section{ACKNOWLEDGEMENTS}

We are very grateful to Dr. Augusto Wagner Padilha Martins, Dr. Fernando Antônio Freitas Lins, Dr. Adão Benvindo da Luz, Dr. João Alves Sampaio and all the staff of the Mineral Technology Center (CETEM/MCT) for the use of the rheometer for the determination of the experimental rheological data. Without it, this work would have been impossible. The authors also acknowledge the Brazilian agencies CNPq, CAPES and FAPERJ for their financial support.

\section{APPENDIX. EXPERIMENTAL CONCERNS}

In the measurement of the viscosity-shear stress data, a Searle-type rheometer ThermoHaake RheoStress 1 (Karlshuhe, Germany) was used. The rheometer works with a Z34 titanium concentric cylinder rotor (DIN 53019/ISO 3219). This rotor is suggested $[46,47]$ for viscosity measurements in the range of $0.7 \mathrm{mPa}$.s to 2400 Pa.s. As the rotor is made of titanium, it is lighter than one of steel, and thus its moment of inertia is smaller [47] $\left(1,540 \times 10^{-5} \mathrm{~kg} \cdot \mathrm{m}^{2}\right)$. Consequently, the error of the measurements in the low values of shear stress or shear strain is lower. The cone angle at the underside of the rotor is $120 \pm 1^{\circ}$ (plane angle) or $4 \pi / 3 \mathrm{sr}$ (solid angle). The torque and speed constants [58] of this rotor are $9080 \mathrm{~Pa} / \mathrm{N} . \mathrm{m}$ $( \pm 0.2 \%)$ and $12,326 \mathrm{~s}^{-1} / \mathrm{rad} . \mathrm{s}^{-1}( \pm 0.5 \%)$, respectively. The distance between the top of the cone up to the external cylinder is fixed at $7.2 \mathrm{~mm}$. The inner cylinder radius is $17.000 \mathrm{~mm}$ and the outer one is $18.428 \mathrm{~mm}$, so the gap between the walls is $1.428 \mathrm{~mm}$. The height of the rotor is $51 \mathrm{~mm}$. As this is a Searle-type 
rheometer, the ratio between the outer and inner angular velocity is null, once the external cylinder is stationary. A thermostatic bath ThermoHaake Phoenix P1-CP25 (Karlshuhe, Germany) (DIN 58966) was employed to control the temperature within $0.01 \mathrm{~K}$. The thermal fluid used was distilled water.

To obtain the desired viscosity values we adopted the following experimental procedure. For each solution, the initial value of the shear stress was fixed at $0.1 \mathrm{~Pa}$. Subsequently, a step run was adopted up to the value of $908.0 \mathrm{~Pa}$. The higher limiting value corresponds to the maximum torque $(100 \mathrm{mN}$.m) given by the drive-cup motor with the employed rotor. The data acquisition was programmed with one hundred different shear stress values, uniformly distributed within the shear stress range $(0.1 \mathrm{~Pa}$ up to $908.0 \mathrm{~Pa})$. In the case of low viscosity solutions (dilute solutions), the dumping of the rotor movement is low, and thus the maximum limit of rotation speed (1200 rpm) is achieved. In these situations, we considered as the superior limit a shear stress value slightly higher than the last one measured, and established two or three acquisitions by shear stress unitary step, i.e., two or three acquisitions to each pascal of increased stress.

To each shear stress value, the measurements were repeated five times to guarantee that the reproducibility of the acquisitions was better than $1 \%$. If a deviation in a certain acquisition was greater than $1 \%$, the data were neglected and a new measurement was taken. Those results were averaged, giving us the viscosity value of a given shear stress. For the measurements with the different shear stress, a delay of $20 \mathrm{~s}$ was imposed before the beginning of the first acquisition, to warrant the system stability.

As already mentioned, all the experimental data used in the calculations is presented in the Supplementary Material.

The maximum value of Reynolds number $(R e)$ observed was 22.16. That is to say, the ratio between the inertial forces and the viscous force in our measurements is much lower than the critical value [59] (circa 2100) for the transition zone between the laminar regime and turbulent one. Thus, we have not observed any conditions of Reynolds turbulence in the measurements.

Concerning the Taylor instabilities, the largest Taylor number ( $\mathrm{Ta}$ ) obtained was 12.76 , i.e., the ratio of the Coriolis force to the viscous force is much lower than the critical value of 3400 required for the formation of the Taylor vortex [22]. Therefore, we have not observed any Taylor turbulences in the measurements either. In addition, the highest Weissenberg number (Wi), i.e., the ratio of the elastic forces to the viscous forces, was only $5.84 \times 10^{-3}$. As this value is considerable lower than the critical value [22] of 30 , we can assume that no elastic bifurcation could occur.

Another problem that may arise in the rheological measurements is that due to the viscous dissipation. In our measurements, however, the highest Brinkman number $(\mathrm{Br})$ found was $1.53 \times 10^{-3}$, which means that the ratio of the amount of generated heat to the amount of heat removed from the material [60] through thermal conduction was negligible, or in other words, the ratio between the heat generated by viscous dissipation and the conduction heat transfer is negligible, and thus the viscous dissipation is not observable [61].

Besides this, we should also comment on the end effects (edge effects). The end effects arise from the fact that the rotor is not infinitely long. Accordingly, it presents limits, edges, corners and angles. One method of accounting for this is through the theoretical approach of Roscoe [62], where a correction is made by an effective increase in cylinder height produced by the presence of the end effect. This correction, for our measurements, was estimated at $1.553 \mathrm{~mm}$, i.e., less than $3 \%$ of the height of the rotor, and it should be expected to compensate this by the cone shape in the underside of the rotor [63-64].

Another approach to account for the end effect was proposed by Wein et al. [65], Wein, Večeř and Tovčigrečko [66], Večeř [67] and Wein [68]. They have shown that the edge effects can be computed by the concept of pseudosimilarity in the $C_{L}$ coefficient through the slip index. As reported [68], the slippage decrease on the $C_{L}$ value in a multi-region description for a $Z 40$ type geometry is around $1.6 \%$. This coefficient for our measurements was negligible.

Relating to this, another phenomenon that we cannot disregard is the possibility that slippage occurs between the solid surface of the rotor and a fluid in flow.

Despite this still being a nebulous research field, where there is no generally recognized approach for their computation, there are some techniques reported in the literature for handling Couette rheometric data when wall slip (true or apparent) is present. The 
pioneer work of Mooney [69] requires experimental data from three different Couette geometries that need to present a fixed set of relationships between their inner and outer radii. Yoshimura and Prud'homme [70] presented a method where only two different geometries are required, but with the same ratio between the radii. Kiljański [71] described a method that also only requires data from two geometries, but with no restrictions on their radius ratios. Yeow et al. [72] proposed a method that can be used without restrictions on the combinations of the radii to resolve the inverse problem, in which the equation that relates the rotational speed to the wall shear stresses in Couette viscometers is treated as an integral equation of the first kind for the unknown shear stress versus shear rate function and the wall shear stress versus slip velocity function. Therefore, a method based on the Tikhonov regularization [73], was used to obtain approximate solutions of these two material property functions simultaneously. Ancey [74] employed a wavelet-vagulette decomposition to solve the referred inverse problem. Actually, Wein e Tovchigrechko [75] proposed a method, also with no restrictions on the values of the radii, based on local filtering of the primary angular velocity-torque data, that gives a nonparametric representation of the shear rate and slip velocity in function of the shear stress.

None of the tested PEG solutions displays a wall slip effect (AWS) [76]. As the sensitivity of AWS viscometry to slip effects depends on the sensor gap thickness, the non-observation of slippage must be expected due to the rather large gap thicknesses of the rotor employed (1.428 $\mathrm{mm}$ for Z34). For detecting very weak AWS effects, it would be necessary to work with much lower gap thicknesses; something in the order of $0.2 \mathrm{~mm}$ [76]. Due to no apparent wall slip effect is observed, no particle migration could have occurred (centrifugal or side effects).

\section{NOTATION}

$\begin{array}{ll}\text { a } \quad= & \text { equation of state parameter }\left(\mathrm{Pa} \cdot \mathrm{L}^{2} / \mathrm{mol}^{2}\right) \\ A_{0} \quad= & \text { adjustable parameter of the model }(\mathrm{L} / \mathrm{mol}) \\ A_{1}= & \begin{array}{l}\text { first coefficient in the power series } \\ \text { expansion }(\mathrm{L} / \mathrm{mol})\end{array} \\ A_{2} \quad=\begin{array}{l}\text { second coefficient in the power series } \\ \text { expansion }\left(\mathrm{L}^{2} / \mathrm{mol}^{2}\right)\end{array} \\ A_{3}=\begin{array}{l}\text { third coefficient in the power series } \\ \text { expansion }\left(\mathrm{L}^{3} / \mathrm{mol}^{3}\right)\end{array}\end{array}$
$\mathrm{A}_{4}=$ fourth coefficient in the power series expansion $\left(\mathrm{L}^{4} / \mathrm{mol}^{4}\right)$
ARD = absolute relative deviation
$\mathrm{b}=\quad$ equation of state parameter $(\mathrm{L} / \mathrm{mol})$
C $=$ solution concentration $(\mathrm{mol} / \mathrm{L})$
$\mathrm{c}_{\mathrm{id}}=$ ideal solution concentration $(\mathrm{mol} / \mathrm{L})$
$\mathrm{F}_{\text {obj }}=$ objective function
MRSD $=$ mean relative standard deviation
$\mathrm{M}_{n} \quad=\quad$ viscosity average molecular weight
ND = number of data points generated by means of the polynomial regression
$\mathrm{N} \tau=$ number of shear stress values
$\mathrm{P}_{\mathrm{n}} \quad=$ adjustable polynomial coefficients
$\mathrm{R}=$ gas constant $(8.314472 \mathrm{~J} / \mathrm{mol} . \mathrm{K})$
$\mathrm{T}=$ absolute solution temperature $(\mathrm{K})$
$\mathrm{Z}=$ osmotic compressibility factor

\section{Greek Symbols}
$\eta \quad=\quad$ viscosity of the solution (mPa.s)
$\eta_{1}=$ viscosity of the pure solvent (mPa.s)
$\eta_{i, \text { calc }}=$ viscosity calculated by the model (mPa.s)
$\eta_{\mathrm{i} \text { exp }}=$ experimental viscosity (obtained by means of polynomial regression of the data from the rheological curve (mPa.s))

\section{Subscripts}

$$
\begin{array}{ll}
\text { calc } & =\text { calculated value } \\
\exp & =\text { polynomial regressed value } \\
\mathrm{i} & =\text { solute species } \\
\mathrm{id} & =\text { ideal solution }
\end{array}
$$

\section{SUPPLEMENTAL MATERIALS}

The supplemental Tables containing the complete set of all experimental and calculated viscosity values for the four PEGs studied can be downloaded from the journal website along with the article. 


\section{REFERENCES}

[1] Coleman BD, Noll W. Foundations of Linear Viscoelasticity. Rev Mod Phys 1961; 33: 239-49. http://dx.doi.org/10.1103/RevModPhys.33.239

[2] Rivlin RS, Sawyers KN. Nonlinear Continucm Mechanics of Viscoelastic Fluids. Annu Rev Fluid Mech 1971; 3: 117-46. http://dx.doi.org/10.1146/annurev.fl.03.010171.001001

[3] Feigl K, Öttinger HC. The equivalence of the class of RivlinSawyers equations and a class of stochastic models for polymer stress. J Math Phys 2001; 42: 796-17. http://dx.doi.org/10.1063/1.1332783

[4] Leonov AI, Padovan J. On a kinetic formulation of elastoviscoplasticity. Int J Engng Sci 1996; 34: 1033-46.

http://dx.doi.org/10.1016/0020-7225(96)00008-0

[5] Wineman A. Nonlinear Viscoelastic Solids - A Review. Math Mech Solids 2009; 14: 300-66. http://dx.doi.org/10.1177/1081286509103660

[6] Bernstein B, Kearsley EA, Zapas LJ. A Study of Stress Relaxation with Finite Strain. Trans Soc Rheol 1963; 7: 39110.

http://dx.doi.org/10.1122/1.548963

[7] Kaye A. Note No. 134 - Non-Newtonian Flow in Incompressible Fluids. Cranfield: College of Aeronautics 1962.

[8] Kaye A. A Bouncing Liquid Stream. Nature 1963; 197: 10011002.

http://dx.doi.org/10.1038/1971001a0

[9] Leal LG, Oberhauser JP. Non-Newtonian fluid mechanics for polymeric liquids: A status report. Korea-Australia Rheol $\mathrm{J}$ 2000; 12: 1-25.

[10] Rouse PE. A Theory of the Linear Viscoelastic Properties of Dilute Solutions of Coling Polymers. J Chem Phys 1953; 21: 1272-80.

http://dx.doi.org/10.1063/1.1699180

[11] Zimm BH. Dynamics of Polymer Molecules in Dilute Solution: Viscoelasticity, Flow Birefringence and Dielectric Loss. J Chem Phys 1956; 24: 269-78. http://dx.doi.org/10.1063/1.1742462

[12] Cerf RJ. La Macromolecule en Chaine dans un Champ Hydrodynamique - Theorie Generale - Proprietes DynamoOptiques. Polym Sci 1957; 23: 125-50. http://dx.doi.org/10.1002/pol.1957.1202310314

[13] Zimmerman RD, Williams MC. Evaluation of Internal Viscosity Models. Trans Soc Rheol 1973; 17: 23-46. http://dx.doi.org/10.1122/1.549294

[14] Bazúa ER, Williams MC. Rheological Properties of Internal Viscosity Models with Stress Symmetry. J Polym Sci Polym Phys 1974; 12: 825-48.

http://dx.doi.org/10.1002/pol.1974.180120501

[15] Doi M, Edwards SF. The Theory of Polymer Dynamics. New York: Oxford University Press 2001.

[16] Carreau PJ, De Kee DCR, Chhabra RP. Rheology of Polymeric Systems: Principles and Applications. Munich: Carl Hanser Verlag 1997.

[17] Bird RB, Stewart WE, Lightfoot EN. Transport Phenomena. $3^{\text {rd }}$ press. New York: John Wiley \& Sons, Inc. 1963.

[18] Eyring HJ. Viscosity, Plasticity, and Diffusion as Examples of Absolute Reaction Rates. Chem Phys 1936; 4: 283-91.

[19] Kincaid JF, Eyring H, Stearn AE. The Theory of Absolute Reaction Rates and its Applications to Viscosity and Diffusion in the Liquid State. Chem Rev 1941; 28: 301-65. http://dx.doi.org/10.1021/cr60090a005

[20] Glasstone S, Laidler KJ, Eyring H. The Theory of Rate Process. New York: McGraw-Hill 1944.

[21] Bouchbinder E, Langer JS. Nonequilibrium thermodynamics of driven amorphous materials. III. Shear-transformationzone plasticity. Phys Rev E 2009; 80: 0311331-0311338.
[22]

Cruz RC, Martins RJ, Esteves MJC, Cardoso MJEM, Barcia OE. Model for Calculating the Viscosity of Non-Newtonian Aqueous Solutions of Poly(ethylene glycol) 6000 at $313.15 \mathrm{~K}$ and 0.1 MPa. Ind Eng Chem Res 2006; 45: 844-55.

McMillan Jr. WG, Mayer JE. The Statistical Thermodynamics of Multicomponent Systems. J Chem Phys 1945; 13: 276305.

http://dx.doi.org/10.1063/1.1724036

[28] Kozak JJ, Knight WS, Kauzmann W. Solute-Solute Interactions in Aqueous Solutions. J Chem Phys 1968; 48: 675-90.

http://dx.doi.org/10.1063/1.1668700

[29] Franks F, Pedley M, Reid DS. Solute Interactions in Dilute Aqueous Solutions, Part 1. - Microcalorimetric Study of the Hydrophobic Interaction. J Chem Soc Faraday Trans 1 1976; 72: 359-67.

http://dx.doi.org/10.1039/f19767200359

[30] Cardoso MJEM, Medeiros JL. A thermodynamic framework for solutions based on the osmotic equilibrium concept -1 . General formulation. Pure Appl Chem 1994; 66: 383-86. http://dx.doi.org/10.1351/pac199466030383

[31] Cruz RC, Esteves MJC, Teixeira RGD, Cardoso MJEM, Barcia OE. Calculation of the Osmotic Pressure and Theta Temperature of Polymer Solutions Through Cubic Equations of State and the McMillan-Mayer Solution Theory Framework. J Macromol Sci Phys 2010; 49: 1083-93. http://dx.doi.org/10.1080/00222341003609641

[32] Cruz RC. Modelagem do Comportamento Reológico de Soluções Aquosas de Polietilenoglicol de Diferentes Massas Moleculares a $298,15 \mathrm{~K}$ e $0.1 \mathrm{MPa}$ (Ph.D. Thesis). Rio de Janeiro: Federal University of Rio de Janeiro 2007.

[33] Cruz RC, Martins RJ, Cardoso MJEM, Barcia OE. Volumetric Study of Aqueous Solutions of Polyethylene Glycol as a Function of the Polymer Molar Mass in the Temperature Range 283.15 to $313.15 \mathrm{~K}$ and $0.1 \mathrm{MPa}$. J Solution Chem 2009; 38: 957-81.

http://dx.doi.org/10.1007/s10953-009-9388-1

[34] Kirinčič S, Klofutar C. Viscosity of aqueous solutions of poly(ethylene glycol)s at 298.15 K. Fluid Phase Equilib 1999 155: 311-25. http://dx.doi.org/10.1016/S0378-3812(99)00005-9

[35] Benchabane A, Bekkour K. Rheological properties of carboxymethyl cellulose (CMC) solutions. Colloid Polym Sci 2008; 286: 1173-80. http://dx.doi.org/10.1007/s00396-008-1882-2

[36] Ebagninin KW, Benchabane A, Bekkour K. Rheologica characterization of poly(ethylene oxide) solutions of different molecular weights. J Colloid Interf Sci 2009; 336: 360-67. http://dx.doi.org/10.1016/j.jcis.2009.03.014

[37] Schlichting H, Gersten K. Boundary Layer Theory. $8^{\text {th }}$ ed. Heidelberg: Springer-Verlag 2000.

[38] Cruz RC. Transições em Baixo Cisalhamento e Evolução da Camada-Limite (Proceedings of the $12^{\text {th }}$ Meeting of the Brazilian Society of Chemistry - Regional Rio de Janeiro). Rio de Janeiro: Brazilian Society of Chemistry 2009.

[39] Cruz RC, Vaz Jr CA. Transitions in low shear by development of the boundary layer (Proceedings of the $5^{\text {th }}$ 
Brazilian Congress on Rheology). Rio de Janeiro: Brazilian Society of Rheology 2010.

[40] Wagner NJ, Brady JF. Shear thickening in colloidal dispersions. Phys Today 2009; 62: 27-32. http://dx.doi.org/10.1063/1.3248476

[41] Hoffman RL. Discontinuous and Dilatant Viscosity Behavor in Concentrated Suspensions. II. Theory and Experimental Tests. J Colloid Interface Sci 1972; 46: 491-506. http://dx.doi.org/10.1016/0021-9797(74)90059-9

[42] Boersma WH, Laven J, Stein HN. Shear thickening (dilatancy) in concentrated dispersions. AIChE J 1990; 36: 321-32.

http://dx.doi.org/10.1002/aic.690360302

[43] Hoffman RL. Explanations for the cause of shear thickening in concentrated colloidal suspensions. J Rheol 1998; 42: 111-23. http://dx.doi.org/10.1122/1.550884

[44] Bender JW, Wagner NJ. Optical Measurement of the Contributions of Colloidal Forces to the Rheology of Concentrated Suspensions. J Colloid Interface Sci 1995; 172: $171-84$.

http://dx.doi.org/10.1006/jcis.1995.1240

[45] Maranzano BJ, Wagner NJ. The effects of particle-size on reversible shear thickening of concentrated colloidal dispersions. J Chem Phys 2001; 114: 10514-27. http://dx.doi.org/10.1063/1.1373687

[46] Ma T, Wang S. Boundary-layer and interior separations in the Taylor-Couette-Poiseuille flow. J Math Phys 2009; 50: 03310101-03310129.

http://dx.doi.org/10.1063/1.3093268

[47] Gebrüder Haake GmbH Rheometer RheoStress ${ }^{\circledast}$ RS150 Sensor systems. Karlsruhe: Gebrüder Haake GmbH 1998.

[48] ThermoHaake GmbH Rheometer RheoStress ${ }^{\oplus} 1$ - Instruction Manual. Karlsruhe: ThermoHaake GmbH 2002.

[49] Whorlow RW. Rheological Techniques. Sussex: Ellis Horwood 1980.

[50] Poling BE, Prausnitz JM, O'Connell JP. The Properties of Gases and Liquids. $5^{\text {th }}$ ed. New York: McGraw-Hill 2001.

[51] Kalashnikov VN. Shear-rate dependent viscosity of dilute polymer solutions. J Rheol 1994; 38: 1385-403. http://dx.doi.org/10.1122/1.550550

[52] Nelder JA, Mead RA. Simplex Method for Function Minimization. Computer J 1965; 7: 308-13. http://dx.doi.org/10.1093/comjnl/7.4.308

[53] Himmelblau DM. Applied Nonlinear Programming. New York: McGraw-Hill 1972.

[54] Huggins ML. The Viscosity of Dilute Solutions of Long-Chain Molecules. IV. Dependence on Concentration. J Am Chem Soc 1942; 64: 2716-18. http://dx.doi.org/10.1021/ja01263a056

[55] Huggins ML. Physical Chemistry of High Polymers. New York: John Wiley \& Sons, Inc. 1958.

[56] Schulz GV, Blaschke FJ. Eine Gleichung zur Berechnung der Viscositäts-zahl für sehr kleine Konzentrationen, [Molekulargewichtsbestimmungen an makromolekularen Stoffen, IX]. J Prakt Chem 1941; 158: 130-35. http://dx.doi.org/10.1002/prac.19411580112

[57] Cline AK, Renka RL. A Storage-Efficient Method for Construction of a Thiessen Triangulation. Rocky Mt J Math 1984; 14: 119-39.

http://dx.doi.org/10.1216/RMJ-1984-14-1-119
[58] ThermoHaake GmbH Test certificate. Karlsruhe: ThermoHaake GmbH 1997.

[59] Bird RB, Stewart WE, Lightfoot EN. Fenômenos de Transporte. $2^{\text {nd }}$ ed.. Rio de Janeiro: LTC 2004.

[60] Song L, Chen Y, Evans JW. Measurements of the therma conductivity of poly(ethylene oxide)-lithium salt electrolytes. $J$ Electrochem Soc 1997; 144: 3797-800. http://dx.doi.org/10.1149/1.1838094

[61] Griskey RG. Transport Phenomena and Unit Operations: A Combined Approach. New York: John Wiley \& Sons, Inc. 2002.

http://dx.doi.org/10.1002/0471722057

[62] Roscoe R. The end correction for rotation viscometers. $\mathrm{Br} \mathrm{J}$ Appl Phys 1962; 13: 362-66. http://dx.doi.org/10.1088/0508-3443/13/7/321

[63] Schramm G. Reologia e Reometria - Fundamentos Teóricos e Práticos. São Paulo: Artilber 2006.

[64] Pahl M, Gleißle W, Laun HM. Praktische Rheologie der Kunststoffe und Elastomere. Düsseldorf: VDI-Verlag 1995.

[65] Wein O, Vecer M, Havlica J. End effects in rotational viscometry I. No-slip shear-thinning samples in the Z40 DIN sensor. Rheol Acta 2007; 46: 765-72.

http://dx.doi.org/10.1007/s00397-007-0180-0

[66] Wein O, Večeř $M$, Tovčigrečko VV. AWS rotational viscometry of polysaccharide solutions using a novel $\mathrm{KK}$ sensor. J Non-newtonian Fluid Mech 2006; 139: 135-52. http://dx.doi.org/10.1016/j.jnnfm.2006.06.007

[67] Večeř M. Experimentální Studium Zdánlivého Skluzu Při Stěně (Ph.D. Thesis). Prague: Institute of Chemical Process Fundamentals 2004

[68] Wein O. Research Report ICPF No. 2/2005 - Edge Effects In Rotational Viscometry. III. ZZ and KK sensors, Total slip pseudosimilarity. Prague: Institute of Chemical Process Fundamentals 2005

[69] Mooney M. Explicit Formulas for Slip and Fluidity. J Rheol 1931; 2: 210-22. http://dx.doi.org/10.1122/1.2116364

[70] Yoshimura AS, Prud'homme RK. Wall Slip Effects on Dynamic Oscillatory Measurements. J Rheol 1988; 32: 5367. http://dx.doi.org/10.1122/1.549963

[71] Kiljański T. A method for correction of the wall-slip effect in a Couette rheometer. Rheol Acta 1989; 28: 61-64. http://dx.doi.org/10.1007/BF01354770

[72] Yeow YL, Choon B, Karniawan L, Santoso L. Obtaining the shear rate function and the slip velocity function from Couette viscometry data. J Non-newtonian Fluid Mech 2004; 124: 4349

http://dx.doi.org/10.1016/j.jnnfm.2004.07.004

[73] Tarantola A. Inverse Problem Theory and Methods for Model Parameter Estimation. Philadelphia: Soc Ind Appl Math 2005. http://dx.doi.org/10.1137/1.9780898717921

[74] Ancey C. Solving the Couette inverse problem using a wavelet-vaguelette decomposition. J Rheol 2005; 49: 441-60. http://dx.doi.org/10.1122/1.1849181

[75] Wein O, Tovchigrechko VV. Rotational viscometry under presence of apparent wall slip. J Rheol 1992; 36: 821-44. http://dx.doi.org/10.1122/1.550319

[76] Wein O. Private communication 2010. 